\title{
Co- and post-seismic slip associated with the 2005 Miyagi-oki earthquake (M7.2) as inferred from GPS data
}

\author{
Satoshi Miura, Takeshi Iinuma, Satsoshi Yui, Naoki Uchida, Toshiya Sato, Kenji Tachibana, and Akira Hasegawa \\ Research Center for Prediction of Earthquakes and Volcanic Eruptions, Graduate School of Science, Tohoku University, Sendai 980-8578, Japan
}

(Received February 6, 2006; Revised December 5, 2006; Accepted December 6, 2006; Online published February 2, 2007)

\begin{abstract}
A large earthquake with M7.2 occurred on August 16, 2005 along the plate boundary off Miyagi Prefecture. Co- and post-seismic deformations associated with this event were investigated to reveal the causal interplate slips using continuous GPS data and geodetic inversion. The coseismic slip distribution shows good agreement with that estimated by seismic waveform inversions. The major slip area is limited to the southeastern part of the rupture area of the previous 1978 event. The post-seismic slip extended to the southwest of the co-seismic slip area. These distinctive features of both the co- and post-seismic slips might be caused by the existence of the locked plate interface, where seismogenic stress has not released yet, in the northern part of the 1978 rupture area.
\end{abstract}

Key words: GPS, asperity, subduction zone, interplate earthquake, coseismic slip, after slip.

\section{Introduction}

Northeastern Japan, where the Pacific plate is subducting at a rate of about $80 \mathrm{~mm} / \mathrm{yr}$ beneath the overriding continental plate, is one of the most active areas in terms of seismicity in the world. Various studies on major interplate earthquakes around this area have revealed that some of those events can be regarded as recurrent ruptures of asperities, which are defined by distributed patches showing large coseismic slips (Nagai et al., 2001; Matsuzawa et al., 2002; Okada et al., 2003; Yamanaka and Kikuchi, 2003, 2004; Hasegawa et al., 2005).

Earthquakes with magnitudes of about 7.5 have repeatedly occurred on the plate boundary east off Miyagi Prefecture (Miyagi-Oki), with an average interval of about 37 years. The most recent one took place in 1978, i.e., the M7.4 Miyagi-Oki earthquake (e.g., Seno et al., 1980). Based on historical records of these recurrent earthquakes, the Headquarters of Earthquake Research Promotion of Japan (HERP) stated that the next Miyagi-Oki earthquake will occur with a probability of about $50 \%$ in the next 10 years after 2003 (HERP, 2003). In response to this assessment, Tohoku University established 13 new continuous GPS stations around the source area of the 1978 event to complement the nationwide GPS network operated by the Geographical Survey Institute of Japan (GSI), GEONET (e.g., Miyazaki et al., 1997).

On August 16, 2005, an interplate earthquake occurred with magnitude 7.2, hereafter referred to as the 2005 Miyagi-Oki earthquake. Okada et al. (2005) carried out the relocation of aftershocks of the 1978 and 2005 events to reveal that the aftershock area of the 2005 event overlapped

Copyright (c) The Society of Geomagnetism and Earth, Planetary and Space Sciences (SGEPSS); The Seismological Society of Japan; The Volcanological Society of Japan; The Geodetic Society of Japan; The Japanese Society for Planetary Sciences; TERRAPUB only with the southeastern part of that of the 1978 event. In addition, they performed a seismic waveform inversion for the 2005 event to estimate the co-seismic slip distribution and found that it also overlapped with the southeastern part of the 1978 rupture area. The surface displacement data derived by the dense GPS network demonstrate clear co-seismic deformation together with post-seismic deformation (e.g., Heki et al., 1997; Hirose et al., 1999; Miura et al., 2004). In the present study, we use GPS data to estimate both co- and post-seismic slip distributions on the plate boundary by means of geodetic inversion methods.

\section{Data}

A nation-wide GPS network, GEONET (GPS Earth Observation Network System), operated by the Geographical Survey Institute (GSI) of Japan, includes more than 1200 stations distributed throughout Japan (Miyazaki et al., 1997) for the purpose of monitoring regional crustal deformation. GEONET data are routinely analyzed using BERNESE software (Hatanaka et al., 2003). Daily coordinates obtained from GEONET are called F2 solutions and made public.

Tohoku University has also been conducting continuous GPS observations in the Tohoku district, the northeastern part of Honshu island of Japan, since 1987 (Miura et al., 1993). The data analysis for the GPS data from the sites of Tohoku University has been carried out using a PPP (Precise Point Positioning) strategy of GIPSY/OASISII (GOA-II) developed by the Jet Propulsion Laboratory (JPL), NASA (Zumberge et al., 1997). The principle of this method is that through the use of global parameters, such as precise ephemerides, clock errors of GPS satellites, and earth rotation parameters, the JPL estimates of which are precisely based on a global GPS observation network, site coordinates can be obtained with high accuracy using data from only one station. We used data from both of these 


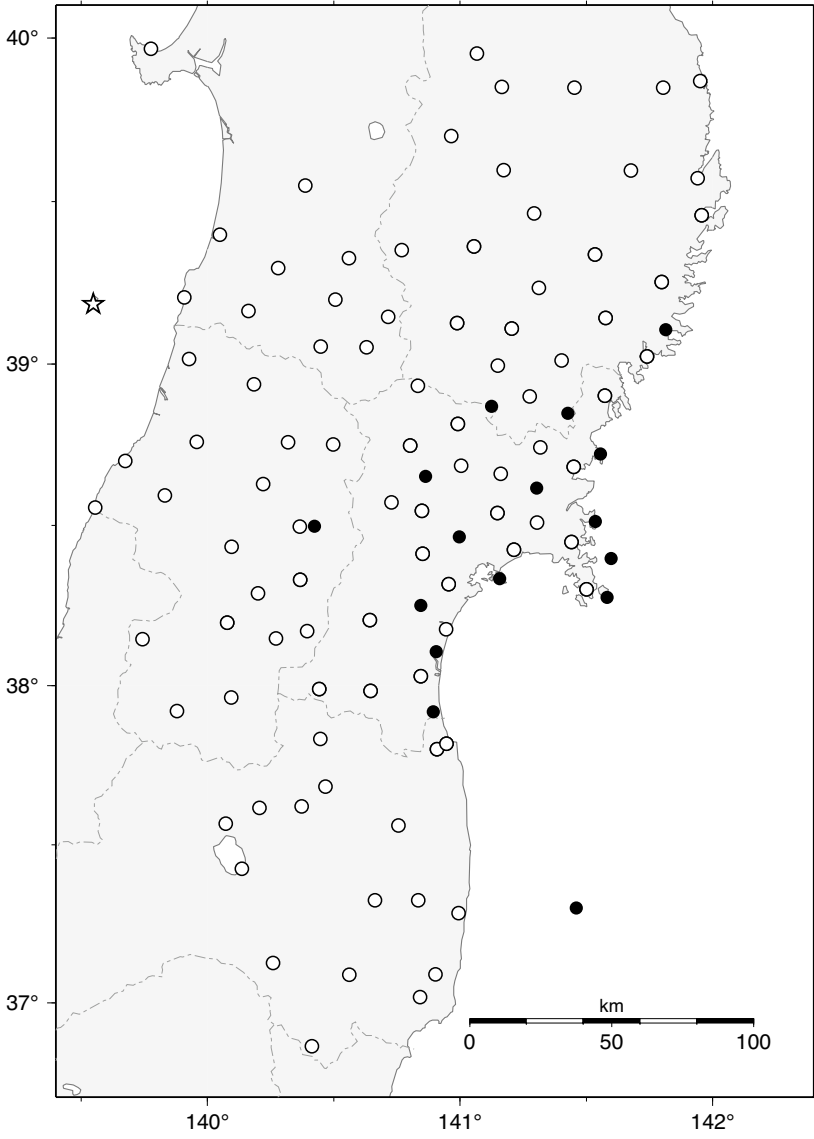

Fig. 1. Location map of continuous GPS stations in the northeastern Japan used in this study. Open and closed circles denote stations conducted by the Geographical Survey Institute of Japan, and Tohoku University, respectively. An open star indicates a GEONET station, 950194 (Tobishima), which is used as a reference station for the baseline analyses.

networks in this study (Fig. 1).

\section{Co-seismic Slip Distribution}

Black arrows in Fig. 2 denote observed co-seisimic displacements associated with the 2005 Miyagi-Oki earthquake at the continuous GPS stations. Co-seismic displacements are defined as differences between averaged site coordinates for 5 days from August 11 and those from August 17. We used the F2 solutions to extract the co-seismic displacements at the GEONET sites and the GIPSY solutions at the sites operated by Tohoku University, assuming that there is no significant bias between two solutions if they are used for the short-term displacement (a few days), such as the coseismic ones.

Horizontal displacements amounting to about $50 \mathrm{~mm}$ were observed near the main shock epicenter. Directions of the co-seismic displacements toward the epicenter suggest that the event was a typical interplate earthquake. We estimate co-seismic slip distribution on the plate interface by applying the geodetic inversion technique devised by Yabuki and Matsu'ura (1992) to these observed displacements. Hasegawa et al. (1994) proposed a geometry of the plate boundary by investigating the seisimicity in the subducting slab, and we adopt this geometry in our model for the plate interface. We assumed a curved fault surface with

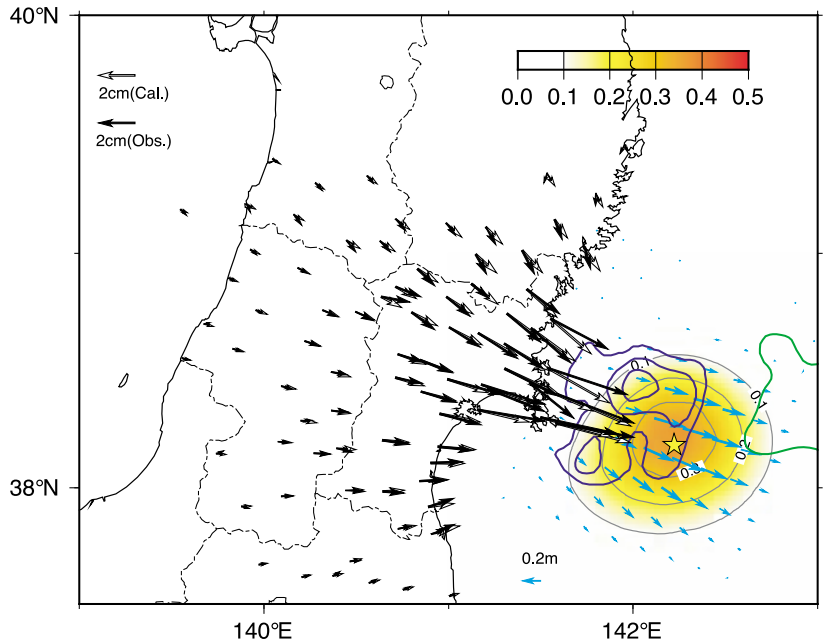

Fig. 2. Co-seismic displacements and slip distribution estimated on the plate boundary. Black, blue and red arrows denote observed displacements, slip vectors on the hanging wall of the plate interface, and calculated displacements from the slip distribution, respectively. Contours of the interplate slip are also shown with a color scale. The yellow star indicates the epicenter of the 2005 Miyagi-Oki earthquake (M7.2). Blue and green contours denote slip distributions of the 1978 (M7.4) and 1981 (M7.0) earthquakes, respectively, estimated by Yamanaka and Kikuchi (2004)

a dimension of $135 \mathrm{~km}$ in the strike direction by $120 \mathrm{~km}$ in dip direction, and co-seismic slip distribution is evaluated as amplitudes of B-spline basis functions located at nine (strike-direction) by eight (dip-direction) grid points. Coseismic slip is constrained to the direction of the relative plate motion (N65W-N115E) $\pm 15^{\circ}$.

Estimated slip vectors on the hanging wall of the plate interface are shown by blue arrows and contours with an interval of $0.1 \mathrm{~m}$ in Fig. 2. Co-seismic displacements calculated from the estimated slip distribution are demonstrated by white arrows. The co-seismic slip is centered around the epicenter of the earthquake denoted by a yellow star. The area of major slip shown by the contour of $0.3 \mathrm{~m}$ covers a southeastern part of the co-seismic slip area of the 1978 event, which was estimated by Yamanaka and Kikuchi (2004). This distinctive feature in the co-seismic slip distribution is also demonstrated by seismic waveform inversions performed by Okada et al. (2005) and Yaginuma et al. (2006). The total seismic moment obtained by integrating the distributed slips shown in Fig. 2 amounts to $6.4 \times 10^{19}$ $\mathrm{Nm}$, which is equivalent to the moment magnitude of 7.1 and almost identical with the result obtained by Yaginuma et al. (2006), as demonstrated in Fig. 7.

\section{Post-seismic Slip Distribution}

Site coordinates at the GPS sites of both GSI and Tohoku University were estimated by GIPSY/OASIS II (Zumberge et al., 1997) with respect to the site 0194 (Tobishima, see Fig. 1) to avoid biases caused by different analysis softwares and strategies. Figure 3 shows the post-seismic displacements observed at four GPS sites of Tohoku University as examples. Note that the linear trends with annual and semi-annual variations estimated for the period from January 1, 2004 to August 15, 2005, and co-seismic displace- 

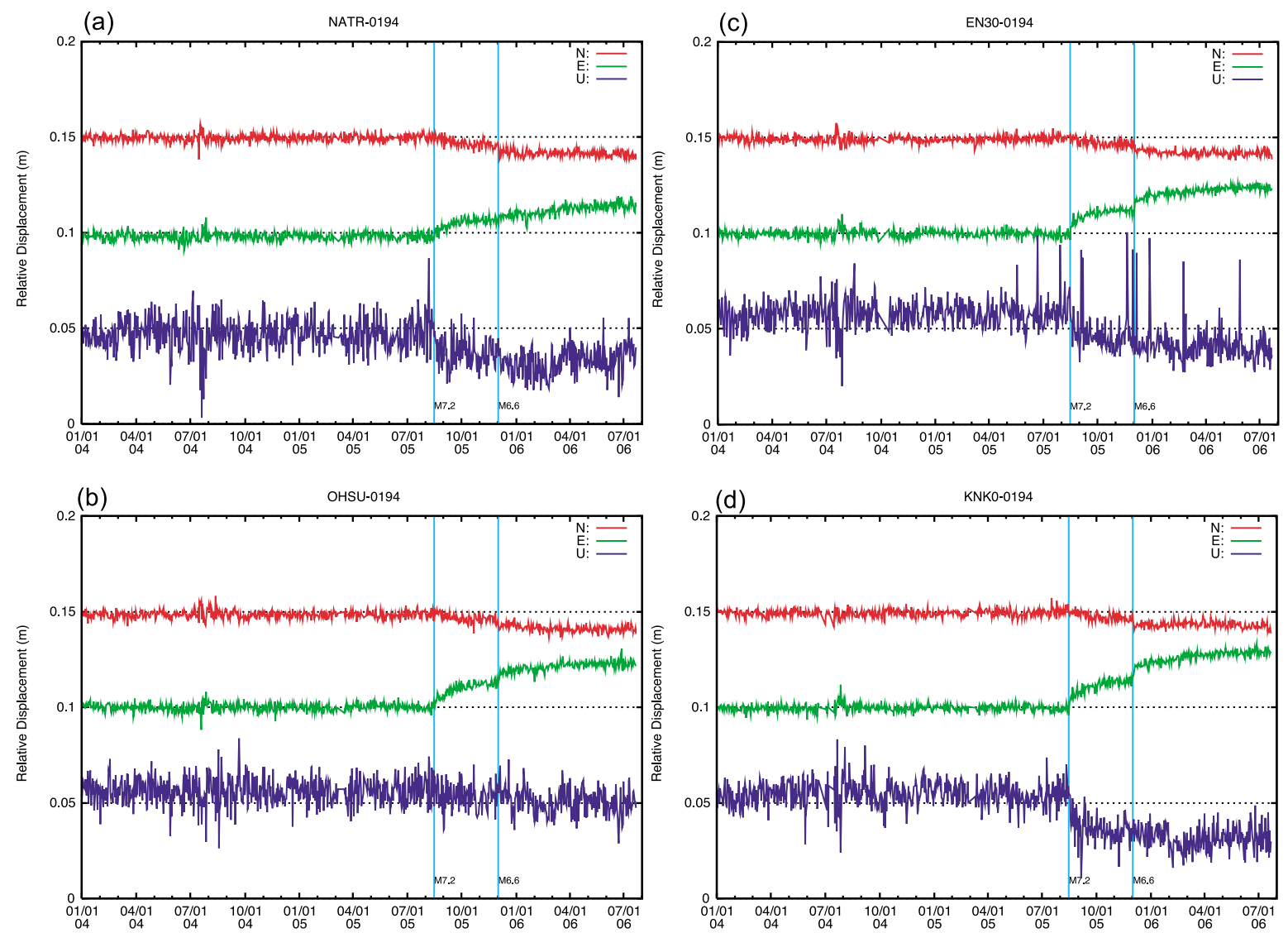

Fig. 3. Time series showing post-seismic displacements at GPS sites of Tohoku University, (a) Natari (NATR), (b) OHSU (Oosu), (c) Enoshima (EN30), and (d) Kinkazan (KNK0). Red, green, and blue traces denote northward, eastward, and upward displacements, respectively. Note that the linear trends with annual and semi-annual variations estimated for the period from January 1, 2004 to August 15, 2005 and co-seismic displacements due to the main shock were eliminated by least square fitting. Two vertical lines denote the times of the main shock and the largest aftershock (M6.6) on December 2, 2005.

(a)

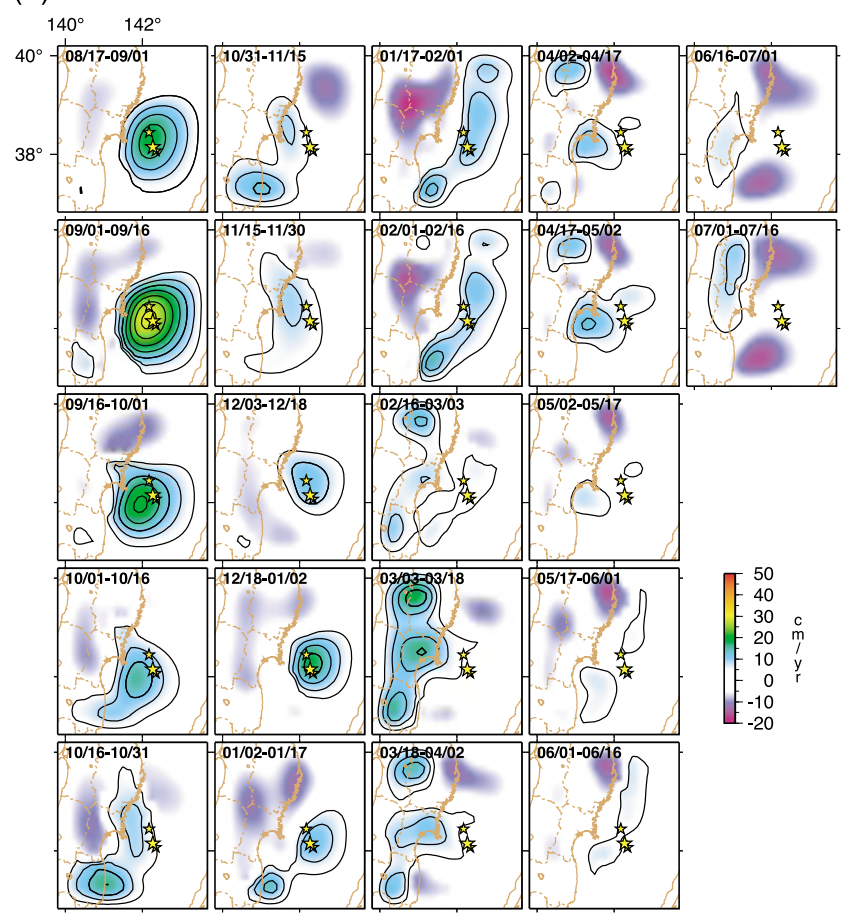

(b)

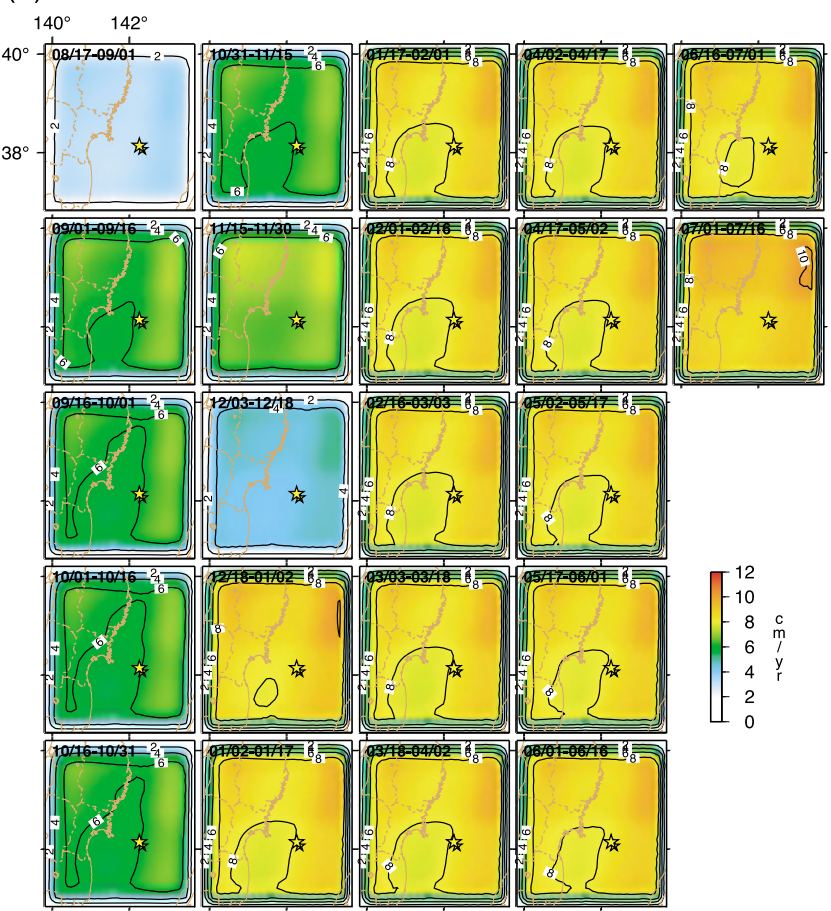

Fig. 4. (a) Snapshots of slip on the plate boundary at 15 -day intervals after the main shock. The contour interval is $5 \mathrm{~cm} / \mathrm{yr}$. Stars indicate the epicenters of the main shock and the largest aftershock. (b) The estimation error corresponding to each snapshot. The contour interval is $2 \mathrm{~cm} / \mathrm{yr}$. 
(a)

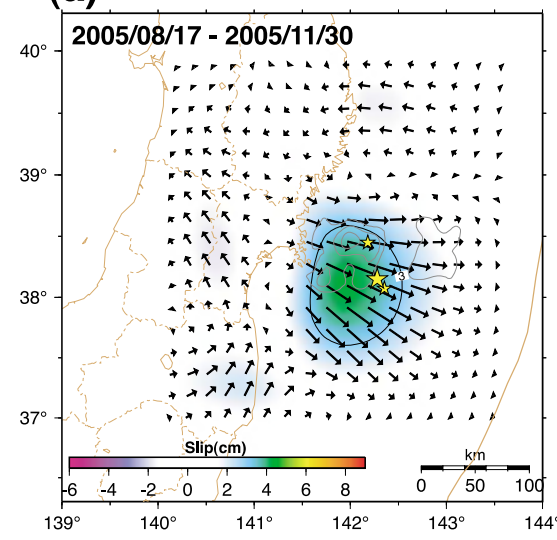

(b)

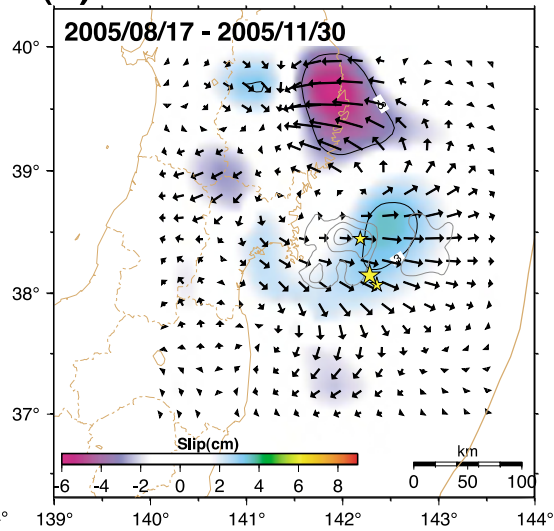

Fig. 5. Cumulative slip distribution for (a) before the largest aftershock (August 17, 2005; November 30, 2005) and (b) after it (December 3, 2005; July 16, 2006). Released moments in the red squares for each period are $3.7 \times 10^{19} \mathrm{Nm}(\mathrm{Mw} 7.0)$, and $3.2 \times 10^{19} \mathrm{Nm}$ (Mw6.9), respectively.

(a)

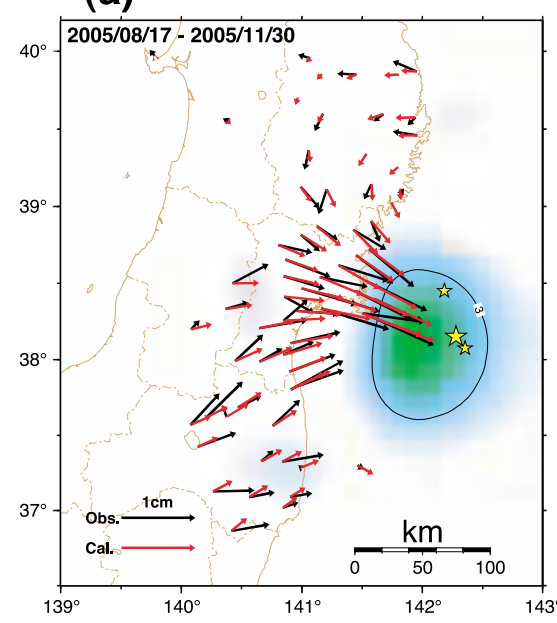

(b)

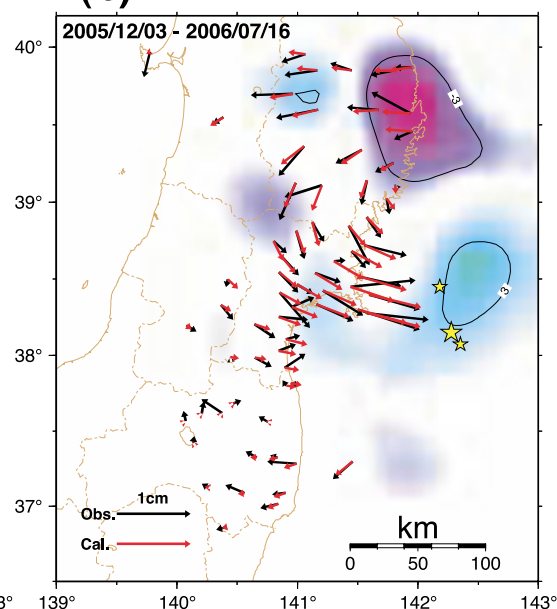

Fig. 6. Comparison between observed displacements (black arrows) and calculated ones (red arrows) from the after slip model for the periods of (a) before the largest aftershock (August 17-November 30, 2005) and (b) after it (December 3, 2005-July 16, 2006)

ments due to the main shock were eliminated from the original time series by least square fitting. A distinctive transient signal dominates at these stations as displacements, directing the SEbE after the main shock, and decays with time from the occurrence of the largest aftershock (M6.6) on December 2, 2005. Minor co-seismic displacements amounting to about $1 \mathrm{~cm}$ were observed to be associated with the largest aftershock. The transient deformation seems to be accelerated a little after the M6.6 event.

Using these time series data, we performed an inversion method devised by Yagi et al. (2003) to estimate the evolution of the fault slip in both space and time. We carried out the inversion individually for the two periods; before and after the largest aftershock. The results are shown in Fig. 4 as the series of snapshots for every 15 days. In terms of the estimation error shown in Fig. 4(b), we may discuss the spatiotemporal evolution of the slip larger than $12 \mathrm{~cm} / \mathrm{yr}$ and 16 $\mathrm{cm} / \mathrm{yr}$ for the periods before and after the largest aftershock, respectively, if we adopt a confidence interval of 2-sigma. For the first 2 months after the main shock, a relatively large post-seismic slip is dominant around the epicenter that tends to move the location of the maximum slip slightly to the

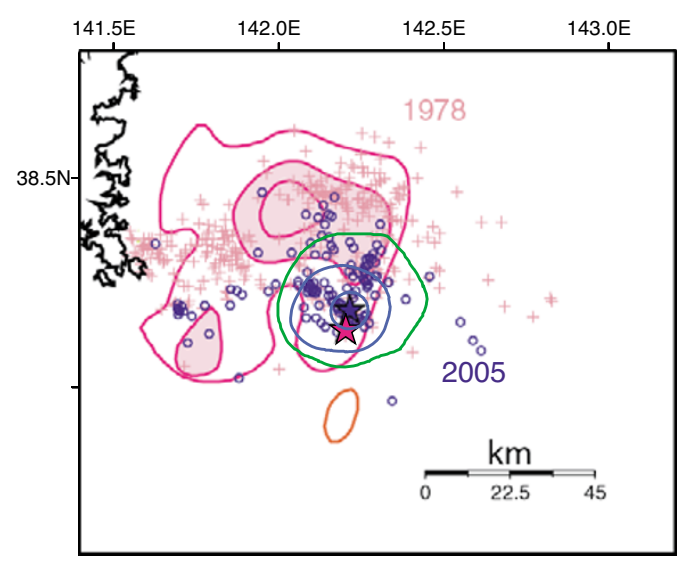

Fig. 7. Comparison of the co-seismic slip distributions of the 2005 Miyagi-Oki earthquake estimated by seismic waveform inversion (blue contours) performed by Yaginuma et al. (2006) and the geodetic inversion using GPS data in this study (green contours) with an interval of $0.3 \mathrm{~m}$. Blue circles and red crosses indicate epicenters of aftershocks for 2 days of the 2005 and 1978 events, respectively, relocated by Okada $e t$ al. (2005). 
southwest. After the largest aftershock, some local maxima of slip exist at each snapshot with slip amounts below the confidence limit, most of these are short-lived, except for the areas around the epicenter and the northern edge of the model fault. The former is the potential after-slip on the plate boundary. The latter, however, demonstrates westward slip, suggesting the strengthened interplate coupling. Ozawa et al. (2006) reported a similar result using more GPS data and assuming a wider fault model.

Figure 5 shows the cumulative slip distribution for the periods before and after the largest aftershock. The after-slip following the main shock is concentrated near the epicenter of the main shock. The location of the maximum slip exists at the southwest of the rupture area of the event, possibly indicating that the major after-slip occurred on the deeper extension of the main shock on the plate boundary. The released moment in the red square in Fig. 5(a) amounts to $3.7 \times 10^{19} \mathrm{Nm}$ (Mw7.0), about $42 \%$ of the coseismic moment of the main shock.

Following the largest aftershock, the major after-slip exists at the eastern neighbor of the 1978 asperity, as shown in Fig. 5(b). Uchida et al. (2006) investigated small repeating earthquakes and suggested that the quasi-static slip occurred as the major aftershock (M6.1) on December 17, 2005, which was located near the maximum slip area of the 1978 event. This may be related to the after-slip shown in Fig. 5(b), even though the location of the slip is different, probably due to the poor spatial resolution in the geodetic inversion caused by the weakness of the signal. Figure 6 shows a comparison between observed displacements and calculated ones from the after-slip model for the periods before and after the largest aftershock.

\section{Discussion}

Okada et al. (2005) carried out precise relocations of main shocks and aftershocks of the 1978 and 2005 MiaygiOki earthquakes to reveal that the 2005 main shock was closely located to that of the 1978 main shock and that the 2005 aftershock area overlaps with the southern/southeastern part of the 1978 case. Okada et al. (2005) and Yaginuma et al. (2006) performed seismic waveform inversions for the 2005 event to demonstrate that the co-seismic slip area of the 2005 event corresponds to the southeastern part of that of the 1978 event. They concluded that the 2005 event can be regarded as re-activation in the part of the coseismic slip area of the 1978 event.

Co-seismic slip distributions both from the waveform inversion by Yaginuma et al. (2006) and the geodetic inversion by this study are compared in Fig. 7. The slip area larger than $0.3 \mathrm{~m}$, which was geodetically estimated and shown by a green contour line, indicates a broader distribution than the result by Yaginuma et al. (2006). However, they agree well in terms of less spatial resolution in geodetic inversion than waveform inversion. The co-seismic slip distribution inferred from independent GPS data also suggests that the co-seismic slip area due to the 1978 event consists of some sub-faults or asperities and that the 2005 earthquake ruptured just the southeastern asperity (Okada et al., 2005; Yaginuma et al., 2006). Conversely, there still remains an asperity not ruptured by the 2005 event.
Figure 7 also suggests the spatial resolution of the geodetic inversion used here. In general, seismic waveform inversion gives a highly resolved coseismic slip distribution when there are sufficient seismographs and the source areas are near observation networks. The rupture area obtained by Yaginuma et al. (2006) shown by blue contour lines in Fig. 7 can be regarded to be more reliable and close to the actual situation. Comparing the area of the $0.3 \mathrm{~m}$ slip in both studies in Fig. 7, our geodetic inversion gives about $50 \%$ larger extent in diameter than the seismological one. It should be noted, however, that the centers of slip areas derived in both studies are almost identical and we may trust the location of it.

Umino et al. (2006) relocated the main shocks and aftershocks of the 1933 (M7.1), 1936 (M7.4), 1937 (M7.1), and 1978 (M7.4) Miyagi-Oki earthquakes and concluded that the three earthquakes in 1930s ruptured different parts of the source area of the 1978 event, i.e., its eastern, central, and western portions, respectively. This result suggests that some asperities exist off Miyagi, as mentioned above, and that the next major earthquakes with magnitudes about 7 will occur in the near future.

Hypocenters of interplate earthquakes are occasionally located remotely from the major slip area. The recent progress in the so-called Asperity Model suggests that various sizes of asperities exist on the plate boundary; large asperities are responsible for the occurrences of large earthquakes, while small ones generate small repeating earthquakes (Matsuzawa et al., 2004). Some of the large interplate earthquakes, such as the 1968 Tokachi-Oki and the 1978 Miyagi-Oki earthquakes, show a few major slip areas (Yamanaka and Kikuchi, 2004), suggesting that large interplate events can be caused by the multiple rupture of asperities. The epicenters located remotely from the major slip areas might be one of the small asperities which triggered the slip on the nearby larger asperities. In the case of the 2005 Miyagi-Oki earthquake, however, the rupture area was rather small, as demonstrated by Yaginuma et al. (2006), and corresponding to its magnitude, the event ruptured a single asperity with the size of about $20 \mathrm{~km}$, and its epicenter coincides with the major slip area.

The Japan Meteorological Agency reported that seismic activity in the southern neighboring area of the 2005 Miyagi-Oki earthquake was relatively lower before the event while it increased a little after it (JMA, 2006). This may related to the occurrence of the after-slip clarified in this study.

The 2003 Tokachi-Oki earthquake was followed by the dominant after-slip lasting for more than 1 year, as reported by Yui et al. (2005). The after-slip area of the 2003 event extended bi-laterally along the trench axis. This feature contrasts strikingly with the results of the present study: the after-slip occurred only down to the south. This might be caused by the existence of the locked plate interface to the north of the 2005 source area.

Suwa et al. (2006) investigated the interseismic deformation from 1997 to 2001 in northeastern Japan to reveal that the co- and post-seismic slip areas of the 2005 Miyagi-Oki earthquake were almost fully locked in that period. We are therefore unable to discriminate the size of the asperities 
where a large co-seismic slip occurs; geodetic studies on interseismic deformation are required for this. Considering the limited spatial resolution in geodetic inversions and the released moment from the transient slip, equivalent to about Mw7.0, it may be too early as yet to conclude that the area to the south of the 2005 event has no potential to cause large earthquakes. Further studies on interplate coupling with higher spatial resolution are required.

\section{Conclusions}

Co- and post-sesimic deformations associated with the 2005 Miyagi-Oki earthquake were investigated to resolve the causal interplate slips, using continuous GPS data and the geodetic inversion. The co-seismic slip distribution estimated by the present study shows good agreement with that estimated by waveform inversions. The major slip area corresponds to the southeastern part of the rupture area of the 1978 event, suggesting that there still remains the locked plate interface, which may cause potential interplate earthquakes in the near future.

The after-slip seems to have extended to the southwest of the co-seismic slippage. This distinctive feature may also be caused by the presence of the asperities, where seismogenic stress has not released yet, in the northern neighborhood. The monitoring of space-time evolution in aseisimic slips occurring on the plate interface would provide a clue to predict occurrences of interplate earthquakes and to understand the process of plate subduction.

Acknowledgments. We thank the Geographical Survey Institute of Japan for providing continuous GPS data. The authors are grateful to Yuji Yagi for providing us a useful inversion program to estimate the spatiotemporal evolution of slip on faults. We appreciate the thoughtful reviews and valuable comments by Hiroaki Takahashi and Takeshi Sagiya. Figures were drawn using Generic Mapping Tools (Wessel and Smith, 1991). We also thank Shinobu Okuyama for her critical reading of the manuscript. This work was partially supported by Grant-in-Aid for Scientific Research, No. 17800002 of the Ministry of Education, Culture, Sports, Science and Technology (MEXT).

\section{References}

Hasegawa, A., S. Horiuchi, and N. Umino, Seismic structure of the northeastern Japan convergent margin: A synthesis, J. Geophys. Res., 99, 22,295-22,311, 1994.

Hasegawa, A., N. Uchida, T. Igarashi, T. Matsuzawa, T. Okada, S. Miura, and Y. Suwa, Asperities and quasi-static slip on the subducting plate boundary east off Tohoku, NE Japan, SEIZE volume, Columbia Univ. Press., 2005 (in press).

Hatanaka, Y., T. Iizuka, M. Sawada, A. Yamagiwa, Y. Kikuta, J. M. Johnson, and C. Rocken, Improvement of the Analysis Strategy of GEONET, Bull. GSI, 49, 11-37, 2003.

Headquaters for Earthquake Research Promotion of Japan, Long-term evaluation of the Miyagi-Oki earthquakes, http://www.jishin.go.jp/ main/index.html, 2003 (in Japanese).

Heki, K., S. Miyazaki, and H. Tsuji, Silent fault slip following an interplate thrust earthquake at the Japan Trench, Nature, 386, 595-597, 1997.

Hirose, H., K. Hirahara, F. Kimata, N. Fujii, and S. Miyazaki, A slow thrust slip event following the two 1996 Hyuganada earthquakes beneath the Bungo Channel, southwest Japan, Geophys. Res. Lett., 26, 3237-3240, 1999.

Japan Meteorological Agency, Seismic Activity in and around the Tohoku District (November 2005-April 2006), Rep. Coord. Comm. Earthq. Pred., 76, 83-93, 2006.

Matsuzawa, T., T. Igarashi, and A. Hasegawa, Characteristic smallearthquake sequence off Sanriku, northeastern Honshu, Japan, Geophys. Res. Lett., 29, 1543, doi:10.1029/2001GL014632, 2002.
Matsuzawa, T., N. Uchida, T. Igarashi, T. Okada, and A. Hasegawa, Repeating earthquakes and quashi-static slip on the plate boundary east off northern Honshu, Japan, Earth Planets Space, 56, 803-811, 2004.

Miura, S., K. Tachibana, K. Hashimoto, E. Murakami, T. Kono, K. Nida, T. Sato, and S. Hori, GPS observation for regional crustal deformation around the northeastern Japan arc, J. Geod. Soc. Japan, 39, 167-178, 1993

Miura, S., Y. Suwa, T. Sato, K. Tachibana, and A. Hasegawa, Slip distribution of the 2003 northern Miyagi earthquake (M6.4) deduced from geodetic inversion, Earth Planets Space, 56, 95-101, 2004.

Miura, S., Y. Suwa, and A. Hasegawa, The 2003 M8.0 Tokachi-Oki earthquake? How much has the great event paid back slip debts?, Geophys. Res. Lett., 31, L05613, doi:10.1029/2003GL019021, 2004.

Miyazaki, S., T. Saito, M. Sasaki, Y. Hatanaka, and Y. Iimura, Expansion of GSI's nationwide GPS array, Bull. Geogr. Surv. Inst., 43, 23-34, 1997.

Nagai, R., M. Kikuchi, and Y. Yamanaka, Comparative study on the source process of recurrent large earthquakes in Sanriku-oki region: the 1968 Tokachi-oki and the 1994 Sanrikuoki earthquakes, Zisin (J. Seismal. Soc. Japan), 54, 267-280, 2001 (in Japanese with English abstract).

Okada, T., T. Matsuzawa, and A. Hasegawa, Comparison of source areas of M4.8+/-0.1 repeating earthquakes off Kamaishi, NE Japan? Are asperities persistent features?, Earth Planet Sci. Lett., 213, 361-374, 2003.

Okada, T., T. Yaginuma, N. Umino, T. Kono, T. Matsuzawa, S. Kita, and A. Hasegawa, The 2005 M7.2 Miyagi-Oki earthquake, NE Japan: Possible rerupturing of one of asperities that caused the previous M7.4 earthquake, Geophys. Res. Lett., 32, L24302, doi:10.1029/2005GL024613, 2005.

Ozawa, S., H. Suito, and T. Imakiire, Coupling state change near Iwate, northeast Japan, after 2003, Program. Abstr. Seismal. Soc. Japan 2006 Fall Meet., P019, 2006 (in Japanese).

Seno, T., K. Shimazaki, P. Somerville, K. Sudo, and T. Eguchi, Rupture process of the Miyagi-Oki, Japan, earthquake of June 12, 1978, Phys. Earth Planet. Inter., 23, 39-61, 1980.

Suwa, Y., S. Miura, A. Hasegawa, T. Sato, and K. Tachibana, Interplate coupling beneath NE Japan inferred from three-dimensional displacement field, J. Geophys. Res., 111, B04402, doi:10.1029/2004JB003203, 2006.

Uchida, N., T. Matsuzawa, S. Hirahara, and A. Hasegawa, Small repeating earthquakes and interplate creep around the 2005 Miyagi-oki earthquake (M=7.2), Earth Planets Space, 58, this issue, 1577-1580, 2006.

Umino, N., T. Kono, T. Okada, J. Nakajima, T. Matsuzawa, N. Uchida, A. Hasegawa, Y. Tamura, and G. Aoki, Revisiting the three M 7 Miyagioki earthquakes in the 1930s: possible seismogenic slip on asperities that were re-ruptured during the $1978 \mathrm{M}=7.4$ Miyagi-oki earthquake, Earth Planets Space, 58, this issue, 1587-1592, 2006.

Wessel, P. and W. H. F. Smith, Free software helps map and display data, Abstr. EOS Tran. Am. Geophys. Union, 72, 445-446, 1991

Yabuki, T. and M. Matsu'ura, Geodetic data inversion using a Bayesian information criterion for spatial distribution of fault slip, Geophys. J. Int., 109, 363-375, 1992.

Yagi, Y., M. Kikuchi, and T. Nishimura, Co-seismic slip, post-seismic slip, and largest aftershock associated with the 1994 Sanrikuharuka-oki, Japan, earthquake, Geophys. Res. Lett., 30, doi:10.1029/ 2003GL018189, 2003.

Yaginuma, T., T. Okada, Y. Yagi, T. Matsuzawa, N. Umino, and A. Hasegawa, Coseismic slip distribution of the 2005 off Miyagi earthquake (M7.2) estimated by inversion of teleseismic and regional seismograms, Earth Planets Space, 58, this issue, 1549-1554, 2006.

Yamanaka, Y. and M. Kikuchi, Source process of the recurrent Tokachioki earthquake on September 26, 2003, inferred from teleseismic body waves, Earth Planets Space, 55, e21-e24, 2003.

Yamanaka, Y. and M. Kikuchi, Asperity map along the subduction zone in northeastern Japan inferred from regional seismic data, J. Geophys. Res., 109, B07307, doi:10.1029/2003JB002683, 2004.

Yui, S., S. Miura, A. Hasegawa, and Y. Yagi, Space-time Evolution of Interplate Slip beneath Hokkaido, Japan before and after the 2003 Tokachioki Earthquake (M8.0) Inferred from GPS, Eos Trans. $A G U, \mathbf{8 6}(52)$, Fall Meet. Suppl., Abstract G51B-0823, 2005.

Zumberge, J. F., M. B. Heflin, D. C. Jefferson, M. M. Watkins, and F. $\mathrm{H}$. Webb, Precise point positioning for the efficient and robust analysis of GPS data from large networks, J. Geophys. Res., 102, 5,005-5,017, 1997

S. Miura (e-mail: miura@aob.geophys.tohoku.ac.jp), T. Iinuma, S. Yui, N. Uchida, T. Sato, K. Tachibana, and A. Hasegawa 